\title{
Do Texto à Enunciação: uma Análise das Implicações Significantes em Projetos de Aprendizagem na Modalidade 1:1
}

\author{
Daniela Stevanin Hoffmann - PGIE/UFRGS - dani @lec.ufrgs.br \\ Patrícia Behling Schäfer - PPGPSI/UFRGS - patriciapbs@gmail.com \\ Léa da Cruz Fagundes - PGIE/PPGPSI/LEC/UFRGS - leafagun@ufrgs.br
}

Resumo: Desde 2007, a Escola Estadual de Ensino Fundamental Luciana de Abreu, em Porto Alegre, integra, na condição de piloto, o Projeto Um Computador por Aluno, sob coordenação do Laboratório de Estudos Cognitivos da Universidade Federal do Rio Grande do Sul. O Projeto UCA vem possibilitando uma série de mudanças na prática pedagógica da Escola. Uma delas é a metodologia de Projetos de Aprendizagem, conjugada com o uso do ambiente virtual para aprendizagem AMADIS. Este artigo apresenta uma análise, sob a ótica da Lógica das Significações (Piaget \& Garcia, 1989), das produções textuais e das enunciações de alunos de $4^{\mathrm{a}}$ série da escola piloto.

Palavras-chave: Projeto UCA; Projetos de Aprendizagem; Significações; Implicações Significantes.

From Text to Enunciation: an Analysis of Significant Implications in Learning Projects in 1:1 modality

\begin{abstract}
Since 2007, the Public State Elementary School Luciana de Abreu, in Porto Alegre, participates as a trial at One Computer per Student (Um Computador por Aluno) Project, under coordination of Laboratório de Estudos Cognitivos from Universidade Federal do Rio Grande do Sul. UCA Project has been providing a series of changes in pedagogic practice of School. One of them is the methodology of Learning Projects, linked to the use of digital environment for learning AMADIS. This paper presents an analysis, by the perspective of Logic of Significations (Piaget $\&$ Garcia, 1989), of textual productions and enunciations of students from $4^{\text {th }}$ grade of the trial school.
\end{abstract}

Key-words: UCA Project; Learning Projects; Significations; Significant Implications.

\section{Introdução}

Desde 2006, o Governo Federal Brasileiro examina a possibilidade de prover as escolas públicas do ensino básico com laptops educacionais de baixo custo como um meio de elevar a qualidade da educação. Cinco escolas brasileiras de diferentes localidades - Brasília/Distrito Federal, Piraí/Rio de Janeiro, São Paulo/São Paulo, Porto Alegre/Rio Grande do Sul e Palmas/Tocantins - integram a primeira etapa da investigação relativa à adoção da modalidade de aprendizagem $1: 1^{1} \mathrm{em}$ desenvolvimento no Projeto Um Computador por Aluno (Projeto UCA).

O Laboratório de Estudos Cognitivos da Universidade Federal do Rio Grande do Sul (LEC/UFRGS), com sua equipe de pesquisadores, professores da UFRGS, graduandos, mestrandos e doutorandos dos Programas de Pós-Graduação em Psicologia Social e Institucional (PPGPSI/UFRGS) e em Informática na Educação (PGIE/UFRGS), tem acompanhado e assessorado a experiência piloto realizada em Porto Alegre na Escola Estadual de Ensino Fundamental Luciana de Abreu (LA). Participam do projeto as turmas do ensino fundamental regular, que utilizam laptops do modelo $\mathrm{XO}^{2}$, elaborado pela organização não governamental OLPC (One Laptop per 
Child), fundada por professores do Massachusetts Institute of Technology (MIT) e idealizadora do projeto, que abrange diferentes países em desenvolvimento.

Anteriormente ao Projeto UCA, as propostas ligadas à inclusão digital nas escolas brasileiras tiveram como modelo o compartilhamento de máquinas por tempo determinado em ambientes de laboratório (modelo "um para muitos"). A introdução da modalidade 1:1 inicia a transição para a lógica da inclusão e da mobilidade que favorece a experiência de apropriação da tecnologia digital e verdadeira imersão do estudante em uma ecologia cognitiva informatizada (Lévy, 1993).

Uma das principais mudanças que acompanham a adoção do modelo 1:1 no piloto de Porto Alegre é a implantação, por parte significativa do corpo docente, da metodologia de Projetos de Aprendizagem (PAs) (Fagundes et al., 2000; Lacerda et al., 2000; Lacerda \& Dutra, 2003) e da utilização do Ambiente de Aprendizagem a Distância AMADIS, que foi especialmente criado para o desenvolvimento coletivo de PAs (Basso et al., 2006; Bittencourt et al., 2006; Monteiro et al., 2005). Criada pelo LEC, a proposta dos Projetos de Aprendizagem, sustentada na concepção de aprendizagem ativa e interdisciplinar em rede, possibilita que os alunos se tornem autores de seu conhecimento, elaborando questões e pesquisando assuntos que lhes sejam de fato relevantes.

Avaliam-se, no piloto, tanto os aspectos técnicos quanto os impactos do laptop sobre o desenvolvimento psico-cognitivo dos aprendizes. Procura-se, a cada dia, avaliar o processo, não quantitativamente porque não há parâmetros estabelecidos para esta situação, mas qualitativamente, observando cada indivíduo e sua relação com o todo e analisando as influências de um no outro. Uma série de artigos e trabalhos em eventos acadêmicos tem relatado e documentado ações e impactos da parceria laptop XO - PA (Hoffmann \& Fagundes, 2008; Hoffmann \& Schwarz, 2007; Kist, Schäfer \& Bittencourt, 2007).

Este artigo analisa, de acordo com a Epistemologia Genética, produções de alunos da $4^{\mathrm{a}}$ série da LA disponibilizadas no ambiente digital AMADIS. A Lógica das Significações (Piaget \& Garcia, 1989) embasa o estudo sobre a autoria das implicações (locais, sistêmicas e estruturais) identificadas nas produções textuais dos alunos e a existência ou não de progressos nas significações elaboradas.

\section{Fundamentação Teórica}

De acordo com Jacques Fontanille (2007, p. 33), a significação é o produto organizado pela análise, atribuindo um conteúdo de sentido a uma expressão. Trata-se de um processo concretizado pelos atos do discurso. Émile Benveniste (1995) distingue duas dimensões da significação: a das unidades da língua, convencional e fixada pelo seu próprio uso, e aquela que contempla o discurso, isto é, realizações lingüísticas concretas ou conjuntos de significantes produzidos por um ato de enunciação. A língua combinaria, assim, dois modos de significação distintos - o semiótico e o semântico: o primeiro designando o modo de significação própria ao signo lingüístico, constituindo-o como unidade, e o segundo configurando-se no modo específico de significação engendrada pelo discurso.

Para Veen \& Vrakking (2009, pg 13), "aprendizagem é o processo mental pelo qual os indivíduos tentam construir o conhecimento a partir de informações, outorgando significados a elas". Assim, o conhecimento surge a partir da interpretação de dados e informações sobre fenômenos e processos que envolvem diferentes conceitos. Os autores, discutindo acerca dos Homo zappiens, nome atribuído por eles à "geração da rede" (pg. 29) que cresce em uma era digital, enfatizam o desenvolvimento sustentado em múltiplos recursos tecnológicos, selecionando dados dentre inumeráveis fontes de 
informação e aprendendo a gerenciar esses fluxos dinâmicos. O Homo zappiens desenvolve habilidades novas e específicas para aprender por meio da investigação e do domínio e controle dos fluxos de informação. Esse novo aprendiz é ativo, adota uma abordagem não-linear e cria as próprias estratégias para resolver problemas e realizar as pesquisas que define, a fim de aprender sobre aquilo que tem necessidade e interesse portanto, significado.

Em Hacia una Lógica de Significaciones (1989), Piaget \& Garcia assinalam que desde os níveis mais elementares, o conhecimento envolve implicações entre significações. Essas significações são atribuídas às propriedades, aos objetos, aos conceitos e às próprias ações do sujeito que resultam da assimilação a partir de observáveis, isto é, daquilo que se pode constatar dos fatos e da interpretação dos dados. A significação de um objeto, portanto, diz o que se pode fazer com ele, dá modos de como descrevê-lo, classificá-lo e conceituá-lo. Toda significação implica a atividade do sujeito, seja na interação com a realidade física ou com o que é engendrado internamente.

A esse respeito, Piaget (1936) destaca:

$\mathrm{O}$ que se evapora é aquilo que foi simplesmente recebido de fora, o que foi registrado ou memorizado sem móvel ativo, sem outro interesse que aquele, totalmente extrínseco, de se curvar ao costume escolar ou mesmo de passar no exame. [...] Um erro que atesta uma pesquisa verdadeira é por vezes mais útil do que uma verdade simplesmente repetida, porque o método adquirido durante a pesquisa permitirá corrigir a falta inicial e constitui um verdadeiro progresso intelectual, ao passo que a verdade apenas reproduzida pode ser esquecida e a repetição é em si mesma desprovida de valor. [...] De um modo geral, a aquisição dos métodos de trabalho é mais importante para o futuro do escolar do que a aquisição de grande número de conhecimentos particulares.

Assim, das ações aos enunciados, as significações resultam de suas aplicações, ou seja, das relações e das coordenações estabelecidas pelo sujeito. A elaboração dessas relações acontece por meio das implicações significantes. Com o surgimento da função semiótica, as implicações entre ações são acompanhadas por enunciados, dando lugar à formação de implicações significantes evidenciadas na linguagem (Piaget \& Garcia, 1989).

A proposta pedagógica dos Projetos de Aprendizagem oportuniza que alunos realizem pesquisas sobre assuntos de seu interesse e sejam ativamente responsáveis por seus processos de aprendizagem. Quando trabalham nos seus projetos, os alunos têm a possibilidade de desenvolver habilidades em formular questões-problema, identificar conhecimentos prévios, pesquisar e buscar informações, analisar e selecionar as que são pertinentes a sua pesquisa, implementar diferentes formas de apresentar e socializar suas descobertas. Esses "iniciantes" projetos de pesquisa são orientados pelos professores que, além de auxiliar o aluno a estruturar sua investigação, buscam explorar os conceitos das diversas áreas do conhecimento que podem ser relacionados aos PAs. Assim, o processo de aprendizagem torna-se cooperativo e interdisciplinar e os conteúdos escolares são explorados e estudados a partir da necessidade gerada pelas investigações dos estudantes (Fagundes et al., 2000; Lacerda et al., 2000).

No trabalho com PAs, várias mudanças podem ocorrer na própria estrutura da escola: o espaço físico da sala de aula tende a passar por uma reconfiguração; as áreas do conhecimento, os professores e os alunos (entre os próprios e uns com os outros) avançam gradualmente rumo à integração; o horário escolar tradicional que trabalha com curtos períodos de tempo progride no sentido da desfragmentação; um novo currículo estrutura-se a partir da mobilidade entre conteúdos; alunos desenvolvem uma postura investigativa; o papel dos professores modifica-se com a substituição da 
transmissão de conteúdo pela construção de conhecimento; a família participa mais ativamente da escola e da aprendizagem dos estudantes; entre outras tantas que este texto não irá tratar (Lacerda \& Dutra, 2003).

Em relação ao desenvolvimento da linguagem e do sistema de significações do aluno em sua pesquisa, a convivência diária com o computador, segundo Pierre Lévy (2004), favorece a apropriação de uma nova tecnologia da escrita, que respalda a mudança das práticas escolares tradicionais, fundamentada na exploração do processo de abstração e da capacidade argumentativa do aluno, por meio de relações em um domínio de "multiinterações" (cf. Primo, 2007). De acordo com o autor, cada novo sistema semiótico abre novas vias ao pensamento: cada nova tecnologia intelectual redefine funções cognitivas. Orientar o interlocutor a determinada conclusão requer compreensão sobre o tema discutido, e compreender um enunciado requer a prévia representação do conjunto de cenas que ele evoca, processos facilitados pela multiplicidade de códigos e recursos do laptop.

O comportamento e as condutas inteligentes da era digital foram delineados a partir dos usos das tecnologias da comunicação e informação. Grande parte da informação necessária está poucos cliques distante do sujeito; o mesmo ocorre no que diz respeito às pessoas que se queira contatar. O convívio constante com múltiplas fontes de informação e as diferentes verdades passíveis de serem difundidas concomitantemente exigem capacidade de análise e seleção, além de propiciarem que a construção de conceitos se dê em redes de amigos/parceiros com que se pode comunicar instantânea e freqüentemente.

A $4^{\text {a }}$ série da Escola Luciana de Abreu, no ano de 2007, dedicou-se ao trabalho com PAs. A prática com projetos foi desenvolvida durante todo o período letivo. Os alunos passaram por diversas etapas nesse processo: abriram uma conta de e-mail e fizeram cadastro no AMADIS; realizaram registros sob demanda da professora, que avançaram para registros espontâneos; construíram projetos de curta duração e pesquisa mínima, que evoluíram para projetos com aprofundamento de pesquisa; superaram o egocentrismo acerca da sua própria produção, estabelecendo vínculos de cooperação com os colegas; etc.

O ambiente digital AMADIS ofereceu suporte ao trabalho com PAs possibilitando interações entre os estudantes responsáveis por um projeto e seus colegas, professores e pesquisadores que contribuem uns com os outros, fazendo questionamentos e oferecendo referências para a construção e sistematização da pesquisa e de conceitos identificados. Desenvolvido pelo LEC, esse ambiente virtual para aprendizagem proporciona aos usuários diversas ferramentas de comunicação e interação, como diário, fóruns, chats, página na WEB, cadastro de projetos e mensagens pessoais. Todos os alunos e professores participantes do projeto têm no ambiente um instrumento de apoio a suas práticas cognitivas e, também, a interações sociais.

No Webfólio, área pessoal do usuário, na qual estão centralizadas suas relações via ambiente, encontra-se o Diário do aprendiz. É onde são feitos registros acerca de suas construções, seus percursos e suas curiosidades. Pensado como meio de livre expressão, apresenta funcionamento similar ao de um blog, uma vez que os dados livremente postados tornam-se públicos aos demais usuários. Trata-se de um espaço muito utilizado pelos alunos, constituindo-se em repositório para os conteúdos, imagéticos ou textuais, produzidos no decorrer dos projetos de aprendizagem. Cada Projeto tem uma área exclusiva, com espaços para publicação das produções e para interação, fundamental no desenvolvimento cooperativo de projetos. Os alunos apresentam registros durante todo processo de pesquisa, expondo sistematicamente suas descobertas. São esses registros que permitem ao professor acompanhar o 
desenvolvimento do projeto e planejar intervenções focadas nos interesses apresentados, relacionando-os, sempre que possível, com conceitos tradicionalmente trabalhados na escola. As intervenções objetivam propiciar o desenvolvimento do aluno em seus sistemas de significações, partindo de constatações sustentadas em observáveis diretos para a consideração de relações entre conceitos, coordenações inferenciais e vínculos causais.

O material dos PAs disponível no ambiente digital possibilita tanto uma análise focada nos enunciados, sob o código escrito, quanto, por meio deles, a realização de intervenções que identifiquem as implicações significantes estabelecidas nos projetos. Uma vez que as significações resultam das relações e das coordenações que o próprio sujeito estabelece sobre o objeto de conhecimento, as interpretações que elabora, durante as pesquisas, dão indicadores de seu pensamento a partir das implicações significantes evidenciadas na linguagem.

Os três tipos de implicações significantes elaborados por Piaget e Garcia são adaptados para a análise das produções escritas da seguinte forma:

- implicação local: os enunciados evidenciam características de reprodução literal dos dados da fonte consultada ou de memorização sem elaboração de sentido. Não há interpretação além do que é observável imediato do objeto. As implicações permanecem restritas a dados limitados e a contextos muito particulares.

- implicação sistêmica: propriedades não diretamente observáveis começam a ser percebidas, não apenas em relação ao objeto em si, mas ao que pode ser dito dele ou da ação sobre ele. As primeiras relações construídas pelo sujeito são observadas ainda que a escrita seja mista (cópia e interpretação) e que não haja intenção de justificá-las.

- implicação estrutural: o sujeito passa a apresentar justificativas sobre as relações que estabelece e as significações que atribui ao objeto de estudo. A enunciação revela conclusões a que chega, indicando interpretações do aprendiz.

A identificação de tais implicações significantes permite acompanhar processos de significação dos sujeitos durante o desenvolvimento dos PAs. De acordo com a Epistemologia Genética, um conceito se forma a partir das transformações dos sistemas de significação do sujeito, num processo contínuo de auto-regulação e coordenações sucessivas ativadas por desequilíbrios nesses sistemas. Assim, o aprendiz ruma da significação à conceituação, complexificando e aprofundando suas aprendizagens.

\section{Análise dos Dados}

Apresenta-se, nesta seção, uma análise das implicações significantes presentes em Projetos de Aprendizagem de dois alunos de $4^{\text {a }}$ série, com idades de nove e dez $\operatorname{anos}^{3}$. As implicações significantes identificadas serão destacadas por sublinhado e índice subscrito ( $\underline{\text { local }}_{1}, \underline{\text { sistêmica }}_{2}$ e estrutural $\left.{ }_{3}\right)$.

\subsection{Sujeito GS (10 anos)}

GS apresenta uma produção escrita própria. Faz, em seu projeto, um levantamento de conhecimentos prévios à pesquisa e questões a serem respondidas. As "certezas" (conforme referência do aprendiz no quadro 1), contudo, parecem proceder de uma pesquisa anterior do aluno, que realiza uma reconstituição pessoal, estabelecendo tanto implicações locais 1 quanto $\underline{\text { sistêmicas }}_{2}$. Ao relatar parte das características físicas dos jacarés, por exemplo, GS centra-se sobre observáveis diretos. Quando se refere à temperatura do animal e sua relação com o gênero, o aluno estabelece relações entre os dados, ultrapassando o contexto imediato e realizando uma 
interpretação. Tal fato fica evidenciado na consulta à fonte: a informação de que a temperatura da incubação dos ovos determina o sexo dos jacarés foi interpretada pelo aluno como evidência posterior do gênero do animal adulto ${ }^{4}$.

O MEU PROJETO

perguntas não respondidas do meu projeto

1)quantos dentes tem o jacaré?

2)quanto pesa?

3) quantos filhotes pode ter?

4)quantos anos vive?

Certezas

O jacaré é um reptel,nasce de ovo, come todo tipo de peixe,se tiver fome come até um um outro jacaré ${ }_{1}$, se pode saber se são macho ou femea pela temperatura da pele,o macho tem a temperatura do corpo quente e a femea tem a temperatura do corpo fria 2 , o jacaré é prdador natural se não encontrar seu almoço que come naturalmente ele é capaz de ir caçar avez e outros animais que conseque caçar,quando se sente ameaçado mostras seus dentes para assustar seu inquilino, eles se camuflão muito bem e quando estão na água eles deixam seu nariz e quando mergulha prend a respiração.

\section{Quadro 1: Postagem no Diário do AMADIS referente ao projeto de GS.}

O jacaré nasce de ovos, os jacarés são répteis, existem 4 espécies de jacarés 1) jacaréaçu, 2) jacaré de papo-amarelo, 3) crocodilo, 4) jacaré, ele pesa de 40 a $80 \mathrm{~kg}$, vive até 100 anos, tem de 40 a 50 ovos, vivem nos matos e lagos da Amazônia, tem de 30 a 40 dentes.

Classe: réptil

Comportamento: grupos

Comprimento: chegam cerca de $6 \mathrm{~m}$

O jacaré-açu tem outros nomes: maimão preto, aruará, jacaré gigante

\section{Quadro 2: Texto produzido por GS por meio da ferramenta livro da atividade Etoys.}

O quadro 3 apresenta a transcrição da entrevista realizada. Durante a intervenção, são observadas também implicações estruturais 3: o aluno responde aos questionamentos com explicações e justificativas sobre as relações que estabelece. A enunciação aponta conclusões a partir de interpretações do aprendiz.

P: Como tu chegaste à idéia do teu projeto?

GS: O motivo foi que assim: primeiro ele me veio à cabeça, né? Daí eu comecei a pensar, daí no final se tornou meu projeto. Daí por enquanto eu 'tô' vendo as espécies em geral do jacaré, o peso, tudinho que 'tá' aqui.

P: Tu podes me dizer o que tu já descobriste?

GS: Leitura do livro no Squeak com alguns ajustes e complementos.

P: Sobre o comportamento o que tu entendes, G.?

GS: Aqui eu entendi que eles ficam em grupos para se protegerem, porque sozinhos eles não conseguem lidar com os predadores 3

P: Eu vi nas tuas postagens que tem uma coisa interessante sobre a temperatura deles. GS: Dá para reconhecer o jacaré pela temperatura do corpo: quando eles são fêmeas, a temperatura é fria, quando são machos é quente e quando eles nascem por isso assim a mãe deles leva eles para banhos quentes, ela coloca no lodo, e a maioria das vezes 0 ovo esquenta porque 'tá' saindo um filhote macho e se o ovo é frio é fêmea 3 .

\section{Quadro 3: Transcrição da entrevista realizada com GS.}

\subsection{Sujeito EN (9 anos)}

A apresentação no diário de EN demonstra um caráter de escrita mista: a aluna coleta fragmentos e realiza sua interpretação sobre parte dos dados. Na busca de definições para os termos desconhecidos, reproduz literalmente as informações 
encontradas (quadro 6) ou utiliza palavras isoladas entre parênteses: "plataforma (palanque)", "sacerdotes (magos)" e "jade (pedra)", por exemplo. As implicações são $\underline{\text { locais }}_{1}$, centradas sobre informações diretamente constatadas a partir das fontes consultadas. Essa característica manifesta-se também nas questões, vinculadas a dúvidas oriundas do texto apresentado. Os quadros 4, 5 e 6 ilustram os atributos apontados.

O meu projeto é dos olmecas e eles são uma antiga cultura pre-colombiana da mesoamerica. Eles construiram centros cerioniais, e também plataforma(palanque) de 45 metros de altura. Eles faziam imagens em pequenas jades etambem grandes cabecas. 1 Minhas perguntas são:

O que é uma cultura pre-colombiana da mesoamerica?

O que é um jade?

Quadro 4: Primeira postagem no Diário do AMADIS referente ao projeto de EN.

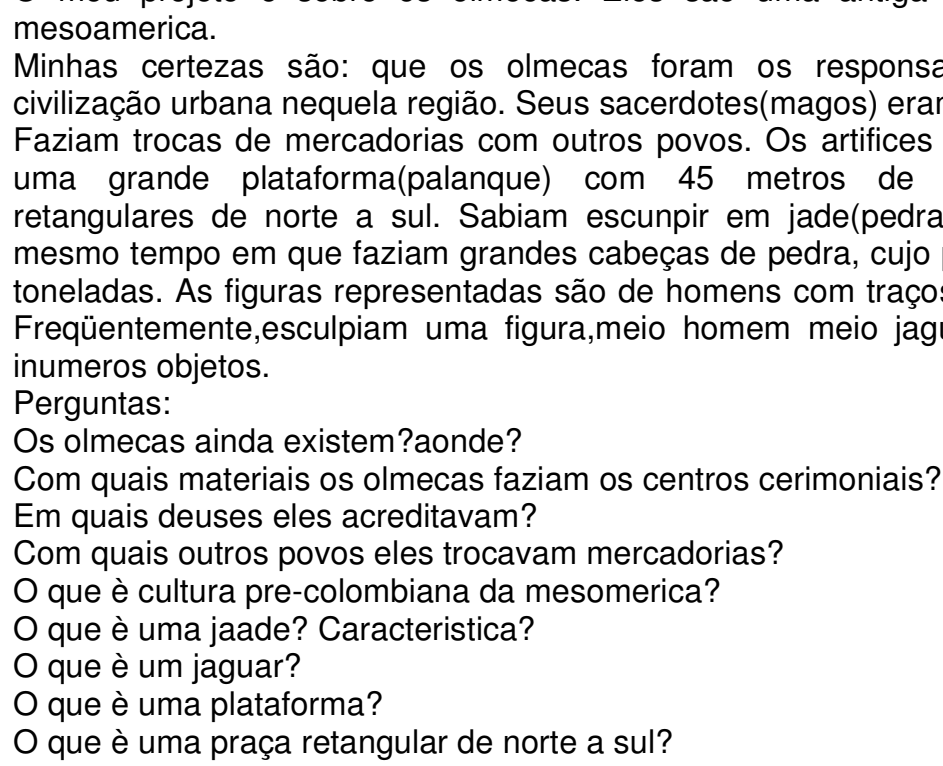

Quadro 5: Postagem realizada por EN na ferramenta Projetos do AMADIS.

\begin{abstract}
Mesoamérica (cuja etimologia grega tem o significado aproximado de America intermédia) é o termo com que se denomina a região do continente americano que inclui aproximadamente o sul do México

Pré-colombiano é o período da história ocorrido antes do descobrimento da América pelo navegador genovês Cristóvão Colombo. O evento da descoberta, entretanto, não é o marco fixo delimitador deste período, já que vastas extensões de terra e muitas populações só vieram a ser atingidas posteriormente. Assim, a expressão "período précolombiano" designa a história ou o estado cultural dos habitantes das Américas, antes de seu encontro com os europeus.

Os olmecas foram uma antiga cultura pré- colombiana da Mesoamériaca qu se desenvouveu nas regiões tropicais do centro-sul do atual México durante o pré-clássico, aproximadamente onde se localzam os estados mexicanos de Veracruz e Tabasco.
\end{abstract}

\title{
Quadro 6: Segunda postagem no Diário do AMADIS referente ao projeto de EN.
}

Após a pesquisa e o registro textual das definições para os termos desconhecidos, EN chega a pistas relevantes sobre alguns significados - a relação entre Mesoamérica e região do México, por exemplo - mas ainda não manifesta características de uma implicação estrutural ${ }_{3}$, o que acontece em seguida: ao tratar do processo de esculpir, a aluna ultrapassa o escopo da pergunta, fazendo referência a uma 
suposta necessidade de registro. Na tentativa de explicar sua conclusão quanto à relação entre a cultura olmeca e a civilização urbana, a aluna denota uma implicação sistêmica 2 , construindo um questionamento sobre o próprio texto relatado sem, no entanto, apresentar o porquê da modificação.

P: Uma das perguntas era o que é a jade, não é?

EN: Isso: era uma pedra pequena que eles esculpiam as coisas. Eles também esculpiam... como é que é o nome? ... Eles tinham deuses, vamos dizer, era o deusjaguar que eles tinham que era tipo, um jaguar eu não sei, isso que eu 'tô' procurando, um jaguar, que eles faziam um jaguar meio homem, agora eu 'tô' procurando o que é jaguar. Algumas perguntas eu já achei 'ó': a cultura pré-colombiana da Mesoamérica eu não sei, Mesoamérica é lá dos mexicanos, essas coisas q eles faziam...

$P: E$ tu entendeste o que é o processo de esculpir?

EN: É que eu acho que eles tinham uma coisa que eles queriam lembrar, daí eles esculpiam coisas deles 3 . Aqui tem mais: eles foram responsáveis pela presença lá no México, no local do México, por lá. E tinham sacerdotes que eram magos...

P: Tu falas da civilização urbana: que eram responsáveis pela presença da civilização urbana. O que tu queres dizer com isso,EN? Como tu chegaste a essa conclusão?

EN: É, mas não foi bem eles que foram responsáveis pela presença da civilização urbana, foi a... ah, esqueci o nome dela, era uma que mandava lá 'num' povo que construiu a civilização urbana, daí eu acho que eles faziam um pouco de parte desse povo. Daí eles pegaram tipo uma parte ${ }_{2}$.

Quadro 7: Transcrição da entrevista realizada com EN.

Conforme os exemplos discutidos, observa-se que não existe, necessariamente, correlação entre escrita e implicação significante. Sobre uma escrita pessoal, por exemplo, pode-se supor a presença de implicações sistêmicas e estruturais que, por meio da intervenção, mostram-se locais. Da mesma forma, uma escrita pessoal constituída, predominantemente, por observáveis diretos da fonte pesquisada pode comportar implicações sistêmicas e estruturais reveladas durante a entrevista. Ou ainda, as escritas com características de reprodutibilidade podem evidenciar a realização de implicações que indicam interpretações, estabelecimento de relações e conclusões próprias.

\section{Conclusões}

O trabalho com Projetos de Aprendizagem supõe uma ação do aluno e uma interpretação - atribuição de significado a essa ação - a fim de que ele venha a construir conhecimento. Para isso, não é suficiente realizar uma cópia de representação da realidade; o aprendiz precisa elaborar sentido sobre os dados que coleta. Com base nos exemplos apresentados, verificou-se que os enunciados não podem, isoladamente, indicar a presença de significação. Por meio de intervenções, ao contrário, torna-se possível realizar um acompanhamento do desenvolvimento das significações atribuídas aos objetos de estudo.

Observa-se que a transição de um método tradicional de educação para a proposta metodológica dos Projetos de Aprendizagem não é intrínseca à modalidade de aprendizagem 1:1. Contudo, os recursos desse modelo ampliam as possibilidades de pesquisa, registro, interação e visibilidade das produções dos alunos. A disponibilidade diária de recursos digitais, para alunos e para professores, permite tanto uma produção constante quanto um acompanhamento sistemático dessa produção.

$\mathrm{Na}$ era digital em que vivemos, a aprendizagem modifica-se ao passo que as crianças de hoje diferenciam-se das de gerações anteriores; infelizmente, isso não ocorre com a instituição escolar. Por mais que os currículos e conteúdos educacionais sejam (re)pensados para serem relevantes e efetivamente adequados para os alunos, suas 
necessidades diretas e futuras - mercado de trabalho, por exemplo -, eles ainda distam do modo de pensar e agir dos aprendizes. Assim, a escola faz parte da vida dessas crianças, mas não as desafia, não as envolve, não as auxilia em suas aprendizagens. Se no cotidiano extra-escolar as crianças executam múltiplas tarefas, gerenciando diferentes níveis de atenção, nas salas de aula o professor é a única fonte de informação. Para elas, essa sala de aula é um ambiente pobre em informações: há apenas uma fonte de informação a ouvir, de caráter obrigatório. O método tradicional de ensino é artificial para esse aluno e, portanto, contraproducente para a aprendizagem.

A teoria das implicações significantes, quando aplicada aos PAs, desde que haja registro regular e intervenção sobre ele, possibilita identificar se e como o pensamento do aprendiz avança com a pesquisa. Da mesma forma que as implicações significantes se complexificam - local, sistêmica e estrutural -, evidencia-se o desenvolvimento das capacidades em estabelecer relações, atribuir sentido, interpretar dados e contrapor esses dados ao conhecimento prévio.

Muitos desafios persistem. É preciso que professores e alunos reestruturem hábitos a fim de valorizar e intensificar os processos de interação e manifestação de hipóteses, relações e compreensões acerca dos objetos de estudo. Transita-se por um caminho de ressignificação da experiência escolar, em que escrita e oralidade são repensadas com vistas à comunicação real.

\section{Notas}

${ }^{1}$ A modalidade 1:1 (um para um) propõe que todos os alunos e professores tenham o seu próprio laptop para ser utilizado em sala de aula e ser levado para casa. São cinco os princípios que guiaram a estruturação do projeto da OLPC: (1) a propriedade do laptop pela criança, que dispõe dele em sua casa, na casa de amigos, em lugares públicos, enfim, conforme sua vontade; (2) público-alvo de baixas idades, para que se possa acompanhar o desenvolvimento cognitivo das crianças desde o início, mesmo sem alfabetização prévia; (3) saturação, a fim de que toda uma escola e, se possível, toda uma comunidade, tenham acesso à tecnologia; (4) conectividade, não apenas à internet mas entre os laptops; e (5) código aberto, ou seja, software livre que pode ser modificado e desenvolvido pelos usuários.

${ }^{2} \mathrm{O}$ modelo XO tem interface, software e hardware diferenciados e de padrão inédito; as chamadas atividades do XO correspondem aos software dos computadores regulares; por exemplo, o Editor de Texto do laptop é considerado uma atividade e não um programa. Para maiores informações, acesse http://laptop.org.

${ }^{3}$ As intervenções transcritas são provenientes da dissertação de mestrado de uma das autoras.

4 "A temperatura é uma variável ambiental que tem papel fundamental na história de vida dos crocodilianos, já que determina o sexo dos indivíduos, o crescimento embrionário e o padrão de termorregulação. [...] A temperatura de incubação dos ovos determina o sexo dos embriões do jacaré-do-Pantanal, Caiman crocodilus yacare. $\mathrm{O}$ ninho incubado a temperatura baixa $\left(<31.5^{\circ} \mathrm{C}\right)$, produzem fêmeas e a temperatura alta $\left(>31.5^{\circ} \mathrm{C}\right)$ produzem principalmente machos".

http://www.agronline.com.br/artigos/artigo.php?id=131.

6. Referências Bibliográficas

BASSO, M. V., MENEZES, C., FAGUNDES, L., NEVADO, R., BITTENCOURT, J. Projetos de Aprendizagem: Uma experiência mediada por ambientes telemáticos. Revista Brasileira de Informática na Educação, Rio de Janeiro, v. 14, n. 1, p. 29-39, 2006. 
BENVENISTE, Émile. Problemas de Lingüística Geral. Campinas: Pontes, 1995.

BITTENCOURT, J., ZORTEA, J., MENDONÇA, R., FAGUNDES, L. Criando uma plataforma para Projetos de Aprendizagem: desafios e reflexões no desenvolvimento do AMADIS. RENOTE. Revista Novas Tecnologias na Educação, v. 4, no. 1, p. 1$10,2006$.

FAGUNDES, L. da C., MAÇADA, D. L., SATO, L. S. Aprendizes do futuro: as inovações começaram!. Brasília: Estação Palavra, 2000.

FONTANILLE, Jacques. Semiótica do Discurso. São Paulo: Editora Contexto, 2007.

HOFFMANN, D. S., FAGUNDES, L. Cultura Digital na Escola ou Escola na Cultura Digital? In: RENOTE. Revista de Novas Tecnologias na Educação, v. 6, no.1, $\mathrm{Jul} / 2008$.

HOFFMANN, D. S., SCHWARZ, C. A formação de professores engendrada pelo uso do laptop educacional no modelo 1:1 In: Simpósio Brasileiro de Informática na Educação, 2007, São Paulo. XVIII SBIE Diversidade da formação, formação na diversidade.

KIST, S. O., SCHAFER, P. B., BITTENCOURT, J. V., FAGUNDES, L. Impacto da modalidade 1:1 nas práticas de leitura e escrita: primeiros resultados. In: Simpósio Brasileiro de Informática na Educação, 2007, São Paulo. XVIII SBIE Diversidade da formação, formação na diversidade. Porto Alegre : SBC - Sociedade Brasileira de Computação, 2007. v. 1. p. 515-525.

LACERDA, R., DUTRA, I., VALENTINI, N. \& CAMARGO, F. Projeto Amora 2000. Disponível em: <http://amora.cap.ufrgs.br/documentos/ProjetoAmora2000.doc > 12 abr. 2001.

LACERDA, R., DUTRA, I. Tecnologias na Escola: algumas experiências e possibilidades. . Revista Novas Tecnologias na Educação, v.1, no.1, p. 1-8, 2003.

LÉVY, P. A Ideografia Dinâmica: rumo a uma imaginação artificial? 2. ed. São Paulo: Edições Loyola, 2004.

LÉVY, P. As tecnologias da inteligência: o futuro do pensamento na Era da Informática. Rio de Janeiro: Editora 34, 1993.

MONTEIRO, V. C., MENEZES, C., NEVADO, R., FAGUNDES, L. Ferramenta de Autoria e Interação para apoio ao desenvolvimento de Projetos de Aprendizagem. RENOTE. Revista de Novas Tecnologias na Educação, v. 3, no. 2, 2005.

PIAGET, J. O trabalho em equipes na escola: notas psicológicas. In: Revista de Educação - Diretoria do Ensino do Estado de São Paulo, set/dez, 1936.

PIAGET, J. \& GARCIA, R. Hacia una Lógica de Significaciones. México: Gedisa, 1989.

PRIMO, A. Interação mediada por computador. Porto Alegre: Sulina, 2007.

VEEN, W. \& VRAKKING, B. Homo Zappiens: educando na era digital. Porto Alegre, Artmed, 2009. 